\title{
J. P. von Westhoff: Six Suites pour Violon seul sans Basse
}

\author{
Előd GÁBOR ${ }^{1}$, Ignác-Csaba FILIP ${ }^{2}$
}

\begin{abstract}
Johann Paul von Westhoff's character was a determining figure of the late $17^{\text {th }}$ and early $18^{\text {th }}$ century. Having a strong impact both on his contemporary fellow composers as well as the future generations like J.S.Bach, J.G.Pisendel, G.Ph.Telemann, etc. For me, Westhoff embodies the perfect $17^{\text {th }}$ century violin virtuoso. Analyzing and playing these magnificient solo suites I found a very obvious similarity between the Bach Solo Sonatas and Partitas and Westhoff's Six Solo Suites for Violin Solo.
\end{abstract}

Key-words: violon, suite, sans basse, Westhoff, Dresden

\section{Introduction}

J.P. von Westhoff was born in Dresden and spent most of his life there. His musical education was first set by his father and later by Heinrich Schütz by that time a well-known violin performer and teacher. Because of his talent in learning multiple foreign languages he got the opportunity to teach Spanish, Italian and also French. He also had the privilege of travelling often all over Europe: Italy, France, the Netherlands and England. Starting 1699 he lived in Weimar, therefore there is a high possibility of him meeting J.S. Bach who was working there as a conductor and organist until 1703.

His heritage consists of a very low number of works. We know from him a continuo accompanied sonata from 1682, a single piece suite for solo violin from 1683 , and the above described six suite series for solo violin from 1696. Some

\footnotetext{
${ }^{1}$ Transilvania University Brasov, gaborelod@gmail.com

${ }^{2}$ Transilvania University Brasov, ignac.filip@unitbv.ro
} 
sources mention a 12 suite volume he wrote in Dresden, but unfortunately there is no written evidence of this.

\section{Discussion}

\subsection{Johann Paul von Westhoff}

Based on Johann Gottfried Walther's work, accomplished in 1732 in Leipzig, J.P. von Westhoff was born in Dresden in 1656 as the second born son of Friedrich von Westhoff, the cavalry captain and trombonist of the Dresden court. His mother and elder sister are never mentioned in any source from that period. His first appearances as a violin virtuoso are dated in two different dates and separate sources: first in 1668 and for the second time in 1674 . Both of them can be considered reliable, as for that period it was not strange the fact that a 12 year old boy could have held a solo concert. The date from 1674 could bear more weight since the mentioned performance was held in Lübeck, his father's hometown (Boyden 1965, 46). Also, the same year he was appointed to the court of Dresden, as a violinist. There are no further mentions of his upbringing or early years.

It is a well-known fact that he spoke fluently several languages. Three years before his debut in Lübeck he taught Spanish, French and Italian lessons to the princes from Dresden, Johann Georg and his younger brother, Augustus II the Strong, who later became the Prince-Elector of Saxony. Although Johann Paul was appointed to a musical career in Dresden, most of his work in court wasn't music related. As mentioned above, his skills as a foreign language speaker kept him traveling a fair deal. As a court member from Dresden and for his merits in foreign language teaching, in 1679 he was appointed to Sweden to attend royal pupils such as the affianced princess of Denmark, the bride to be of the Swedish king. He returned to Dresden around 1680 and during the same year he visited Hungary and joined the battle against the Turkish, under the command of general Schultz. Starting 1681 he starts a traveling lifestyle as a musician. He performs in France, Italy, also in the Netherlands and England. In 1684 Louis the XIV th offers him a golden lace as an award. This award was obviously preceded by numerous compositions presented on the site, even if not written there. One of these pieces was his first suite composed in 1683 and it is known to be the forerunner of his six 
suites composed in 1696 . Is also known as the very first violin piece written without continuo, from a German composer. The piece appeared in a literary magazine named the Mercure Galant. It was published in January 1683, so written supposedly in the year 1682. Westhoff's stay in France during the year 1682 is also confirmed by another piece he published in the same magazine, a continuo accompanied sonata. He got married in 1685 and settled in Wittenberg as a linguistics professor. In 1699 he moved to Weimar and oddly no record of his stay there was registered by Walther's encyclopedia, even though later on Walther himself was pursuing his career in Weimar. From other sources it is known that in 1697 he was still in Dresden as a court member and only later on did he become a professor in Wittenberg, for one-two years. One thing that is known for sure is that he spent his last years of life in Weimar, where he most probably met Johann Sebastian Bach in person. He was 49 years old when he passed away, on the $17^{\text {th }}$ of April, 1705.

\subsection{Historical origin of the suites}

Back in 1696, J.P. Von Westhoff's work was hardly anything that his coeval wouldn't be familiar with. Yet, his six suites for solo violin were to be hidden from the public eye for the next 250 years. Their existence is first mentioned in 1971. Ever since, these marvelous violin pieces are considered the forebearers of Johann Sebastian Bach's Solo Sonatas and Partitas. They were initially dedicated by Westhoff to Christine Eberhardine von Brandenburg-Bayreuth. A few musical scientists see a connection between the first suite created in 1682 and the following six suites in 1696 , as many similarities can be observed in the compositions. Another fact that would corroborate the connection is the Allemandes of the suites, offering an undeniable resemblance. Unfortunately the forgotten suite series of 1696 had no written manuscript as a heritage for future generations. All that is left behind are two copies of the first publishing. In 1971 Várnai Péter reintroduced the six suites. He found them in the Somogyi library in Szeged (Hungary), where it initially got delivered in 1913 with many other compositions. In 1974 the suites were published simultaneously by two publishers: the Peters in Leipzig and Amadeus. Both of them had it written in modern five line musical staff. The Peters managed to include in a volume an almost flawless, accurate URTEXT score completed by additional scientific notes. The Amadeus version was however filled with unnecessary 
scribbles and observations which were often lacking in style. Várnai Péter's work was driven of course by good intentions meant to "ease" the interpretation of the performing artist, but instead he actually complicated the musical sheet. The piece later unveiled in Szeged had its cover missing, therefore unfortunately the title, together with the second part of the Gigue got lost. In this way the suite begins with the French recommendation and finishes with the date of July the $6^{\text {th }} 1696$, together with the location and its composer's name. Westhoff's solo violin pieces title was never recovered and that raises many questions. However the French recommendation sheds light on a few interesting facts. Even though Westhoff was born in Dresden, due to his father's origin in Lübeck he was never well received by his fellow colleagues. It is also interesting the fact that he thanks the acceptance of the Westhoff family at court not to Augustus II the Strong the Prince-Elector of Saxony, but to his wife, even though he was in his service throughout all his youth as a linguistics professor. Last but not least, we also find out an important information from the recommendation: it seems obvious that in 1696 Westhoff was still appointed to the court in Dresden, if not in person but at least on papers. Westhoff's style in the six suites can be considered so rare that we can call it straight unique in the musical history. The composer noted his piece on an eight line staff where the top and bottom part contain three line staff, while the middle two has more space separating it (Figure 1). It is not certain - as a result of the missing cover and its missing title - that the piece was written for violin. Westhoff's father, as an addition to being a court trombonist, also played the lute. Henceforth one can pose the question: why exclude the option that the piece was in fact written for lute? Until the middle of the $18^{\text {th }}$ century the lute was a very popular musical instrument. Since the question posed above seems very appropriate, I shall try my best to offer proof to the contrary. From the description offered by J.G. Walther, Westhoff was considered to be the era's virtuoso in solo violin pieces, so his heritage known to the public only consists of violin compositions. Also, a fact worth mentioning is that the register covered by violin could not be obtained by lute or any other instrument. By the course of the study offered by the musical sheet that was the first restored edition of Westhoff's work, and in comparison to the tablatures or any other methods mentioned that were written to be performed by lute or any other instrument, we can question its likelihood. We must also reason with the fact that never before or ever since in the musical history, Westhoff's method was mentioned or used by any other composer. This can lead us to an obvious conclusion: that in fact not one of his contemporary colleges - in 
spite of the eight line staff magnitude of excellency - could read the piece. Even though visually it doesn't resemble so much, there is a similarity to be considered in his work and Biber's Rosary scordatures. As if both composers intended to use a "secret" writing to create their compositions (Aschmann, 1962, 144-145). Each of Westhoff's six suite series were written in Allemande - Courante - Sarabande Gigue lot order. Something additional to the composition can be noticed at the bottom of each page where he inscripts the suites tonality: a-minor, A-major, Bmajor, C-major, d-minor, D-major order (the conception here resembles to Johann Sebastian Bach's Das wohltemperierte Klavier). In Westhoff's suites, as well as those of Biber the polyphony runs out during the melodiousness and is overtaken by the technical whits in exchange. In his suites however we can recall a more complex example of his contrapuntal imitation, a method used with predilection by Bach in his fugues, 25 years later.

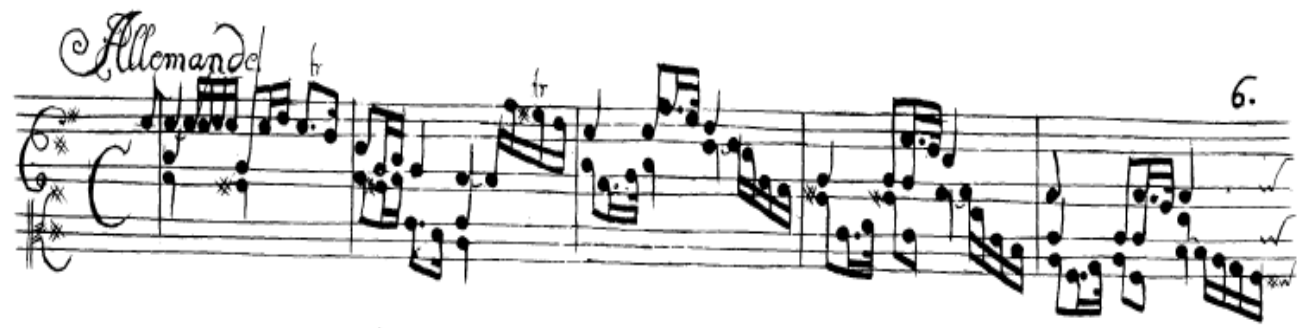

Fig.1. Westhoff's A-major suite, Allemande

Facsimile 1696

\section{Allemande}

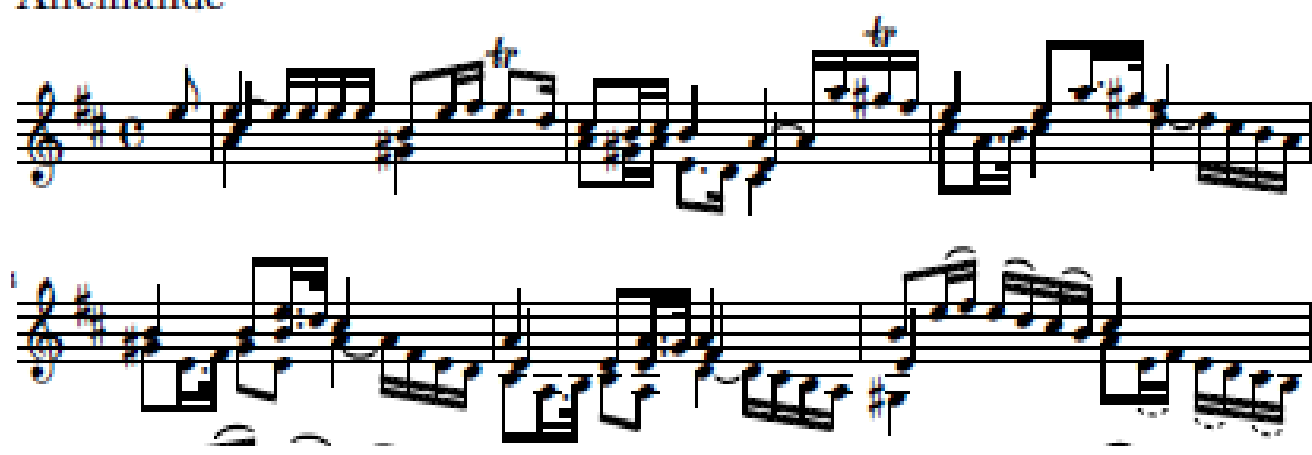

Fig.2. The same Allemande part from the A-major suite transcribed in modern score. 
While studying the Westhoff suites, I often encountered surprising and unsolvable questions. Since the suite series were published in a French journal, it seems obvious that the journal had an independent music sheet graphic designer, specialized in this domain, who more or less engraved the newly written works in copper. This fact is supported by the similarity of the musical notation, i.e., regardless of the author, all music sheets published in the journal come from the same hand. We are talking about a very experienced master here, because, if we give it more thought, it would have been quite difficult to use different keys, modifiers, lines, legatos, music note templates, so they used the so-called intaglio technique (Donington, 1978, 54). With this technique, the music sheet graphic designer writes, engraves the given work in copper with mirror writing. This is the reason why there is a small frame around the contemporary music sheet engraved on the copper plate, this is the trace of a copper plate imprinted on the paper. Here I would note that the images in contemporary books were made using the same procedure. Unlike the music sheet, the written texts were printed using the socalled letterpress technique, that is, they were reproduced with individually locked template letters. In this procedure, the letters are usually sunk into the paper until they are embossed on the other side of the sheet. The Westhoff suites were also printed with such techniques, i.e., the text with letterpress printing, while the music sheet was printed using the intaglio technique. It can be noticed that in the French text of the recommendation on the title page, many of the diacritics are "incomplete", so someone later added and corrected them. I mentioned earlier that Westhoff had a very good sense of language, so it is possible that the author himself would have corrected the text. While studying these works I discovered that, interestingly, there are corrections made on the music sheets as well, with a completely different kind of ink. I think there are two kinds of explanations: the (text) proof-corrector of the journal could have used a different kind of ink (although it is unlikely), or the author himself could have corrected it. It also seems evident in the preface to the Peters edition that the corrections come from Westhoff's pen. Personally, I find the above statement that Westhoff himself would have made corrections in the suite series a bit questionable. In addition to the difference in colour and quality of ink used for correcting the content, there are places such as the almost conspicuous \# mark in the Sarabande set of the first suite, which was not at all "in vogue" at the time. In Westhoff's works, without exception, we will always encounter the $\boldsymbol{x}$ mark. In the Courante set of the second suite, the modification sign, originally marked with $\boldsymbol{a} \boldsymbol{b}$, has been rewritten into the 
cancelling sign still in use today, which is also not found in Westhoff's works. While it is true that the above-mentioned modification signs were already noted down by Bach in the current form, 15 to 20 years later, these modifications suggest that the corrections in the suite series were done years later. The other questionable reason is that most of the modifications were made in places where it is difficult or impossible to perform the violin part. Examples of such impossible parts are the double-stops on the E- and the D-string (in the same time). In such cases, there are obviously solutions (string skipping arpeggios, etc.) that may be more or less effective. As in Biber's Passacaglia, in Westhoff's suites we can also discover sections that are occasionally unplayable in terms of instrumentation. I believe that the composers, especially in the $17^{\text {th }}-18^{\text {th }}$ centuries, thought more like musicians, and thus, following the logic of the vocals, certain errors may have slipped in. This explanation seems much more obvious to me than that asserting that such a violin virtuoso like Westhoff would have made mistakes like those we might find in the "corrected" suites. Obviously, the question arises as to whether the errors I have named are errors at all and if so, how contemporary and authentic are the corrections. One thing is for sure, however, the corrections were made having a clear vision, as in many places the music sheet was scratched and rewritten quite roughly and permanently.

\section{Conclussion}

In this article I had the intention of offering an insight to the reader into J.P. von Westhoff's six suite composed in 1696, a work that was not merely thought as lost, but its existence was unknown until 1971. I believe that the history, origins and development of this genre should be well known If not to all musical performers but at the very least to all violin players.

\section{Acknowledgements}

I would like to thank Ulrike Titze, leader and concertmaster of the Dresdner Barockorchester, who helped me with different informations about the Six Suites 
for solo violin by Johann Paul von Westhoff. Also I want to say a big thank's to my friends who helped me with the English translation.

\section{References}

Aschmann, Dr. Rudolf. 1962. Das deutsche polyphone Violinspiel in 17. Jahrhundert. Zürich.

Boyden, David D. 1965. The History of Violin Playing from its Origin to 1761. London: Oxford University Press.

Donington, Robert. 1978. A barokk zene előadásmódja. Budapest: Zeneműkiadó. 